\title{
saki
}

Studi Akuntansi \& Keuangan Indonesia

\section{FAKTOR-FAKTOR PENGARUH NILAI PENEMPATAN DEPOSITO RUPIAH NASABAH INDIVIDU DI JABODETABEK}

\author{
Aloysius Raino Bawono \\ Miranda \\ Sekolah Bisnis dan Ekonomi, Universitas Prasetiya Mulya \\ Edu I No. 1, Serpong, Jl. BSD Raya Utama, Pagedangan, Tangerang, Banten 15339 \\ Corresponding Author: ...
}

\begin{abstract}
This research aims to investigate the factors that significantly affect the placement of customer funds on BUKU 4 banks' time-deposits in Jabodetabek. Researcher use the questionnaires that were distributed to 405 respondents to capture perceptions on factors that have been tested previously, such as interest rate, service facilities, and promotion. Researcher added the trust factor and word-of-mouth variables in this study. The result is the interest rate and trust factor have a significant impact on the placement of customer's funds on BUKU 4 banks' time-deposit in Jabodetabek. While the service quality, word of mouth, and promotion do not affect significantly.
\end{abstract}

Keywords: bank's time deposit, interest rate, service quality, trust, word-of-mouth, promotion

\section{SARI PATI}

Penelitian ini bertujuan menyelidiki faktor-faktor signifikan yang mempengaruhi nilai penempatan dana nasabah individu pada produk deposito rupiah bank BUKU 4 di Jabodetabek. Peneliti menggunakan kuisioner yang disebar kepada 405 responden untuk memahami persepsi kepuasan nasabah terhadap faktor-faktor seperti: suku bunga, fasilitas pelayanan, dan promosi. Peneliti menambahkan faktor kepercayaan dan word of mouth dalam penelitian ini. Kesimpulan penelitian ini bahwa faktor suku bunga dan kepercayaan memiliki pengaruh signifikan terhadap nilai penempatan dana nasabah pada produk deposito rupiah bank BUKU 4 di Jabodetabek. Sedangkan faktor kualitas layanan, word of mouth, dan promosi tidak memiliki pengaruh signifikan.

Kata Kunci: Deposito, Suku Bunga, Kualitas Layanan, Kepercayaan, Word of Mouth, Promosi

\section{PENDAHULUAN}

Bank, dengan fungsi utama funding dan lending, berperanan sangat penting dalam menggerakkan kegiatan perekonomian suatu negara. Bank berperan melakukan investasi, pengiriman uang, pembayaran serta penagihan, dan untuk melakukan penukaran mata uang asing. Bank juga berfungsi sebagai penyalur dana kredit bagi pelaku usaha di Indonesia. Bank Rakyat Indonesia (BRI), Bank Mandiri, Bank Central Asia (BCA), dan Bank Negara Indonesia (BNI) tergolong dalam BUKU 4 (Bank Umum Kelompok Usaha) dari segi aset yang dimiliki.

Penelitian ini diharapkan membantu bank menentukan fokus dan strateginya dalam meningkatkan jumlah dana deposito nasabah individu. Bagi masyarakat diharapkan memberikan informasi mengenai faktor-faktor yang mempengaruhi individu dalam memilih bank dan menempatkan dananya dalam produk deposito. Penelitian ini bisa menjadi acuan penelitian selanjutnya sehingga memberikan hasil yang lebih baik dan berdampak besar bagi yang membutuhkan.

Penelitian ini menjawab pertanyaan: "Apakah faktor suku bunga, kualitas layanan, kepercayaan, word of mouth, dan promosi sebuah bank mempengaruhi nilai penempatan dana 


\section{saki}

Studi Akuntansi \& Keuangan Indonesia

deposito yang dimiliki oleh nasabah individu? Batasan penelitian ini adalah dana deposito pihak ketiga nasabah di Jabodetabek pada Bank BUKU 4 (BRI, BCA, BNI, dan Bank Mandiri).

\section{PANORAMA/LANDASAN TEORI}

Bank ialah badan usaha penghimpun dana masyarakat dalam bentuk simpanan dan menyalurkannya kepada masyarakat dalam bentuk kredit dan/atau bentuk-bentuk lainnya untuk meningkatkan taraf hidup rakyat banyak, (UU No. 10 tahun 1998). Bank adalah lembaga keuangan penghimpun dan penyalur dana dari dan ke masyarakat serta pemberi jasa-jasa perbankan lainnya, (Kasmir 2005:9). Bank memiliki fungsi sebagai agent of trust, agent of development, dan agent of service, (Lubis, 2010:10 dalam Tambunan dan Nasution, 2013:195).

Deposito adalah simpanan yang penarikannya hanya dapat dilakukan pada waktu tertentu berdasarkan perjanjian antara nasabah dengan bank, (UU No. 10 tahun 1998). Pemilik deposito/deposan diberikan imbalan atas dana yang disimpan dalam bentuk pembayaran bunga. Beberapa deposito bank yakni; deposito berjangka, dan sertifikat deposito, deposit On Call.

Suku bunga/bunga bank adalah bentuk balas jasa bank kepada nasabah yang mempercayakan dananya disimpan dalam berbagai bentuk produk perbankan. Tingkat suku bunga tiap bank berbeda-beda tergantung kebijakan masing-masing. Suku bunga terbagi menjadi dua yaitu bunga simpanan dan bunga pinjaman, (Kasmir 2012). Keduanya saling mempengaruhi dan merupakan komponen utama pendapatan serta pengeluaran bank. Faktor-faktor pengaruh tingkat suku bunga simpanan dan pinjaman yakni kebutuhan dana, persaingan antar bank, kebijakan pemerintah, dan jangka waktu (Kasmir, 2012).

Pelayanan adalah suatu tindakan salah satu pihak yang menawarkan pihak lain sesuatu yang tidak berwujud dan tidak menimbulkan kepemilikan atas apapun (Kotler, 1997). Kualitas layanan perusahaan memiliki hubungan positif dengan perilaku konsumen untuk merekomendasikan kepada orang lain tentang pelayanan tersebut, (Penelitian Parasuraman et al. 1988). Pengukuran kualitas layanan quality dilihat dari: reliability (Keandalan), responsiveness (Cepat Tanggap), empathy (Peduli), assurance (Kepastian), tangibility (Fasilitas Fisik).

Menurut Moorman et al. (1992) dalam Gill et al. (2006), kepercayaan adalah keinginan mengandalkan rekan pertukaran yang dapat dipercaya. Tingkat kepercayaan dapat meningkatkan level kooperasi dan menurunkan tingkat risiko dan ketidakpastian, (Coulter dan Coulter (2002:36).

Word of Mouth (WOM) atau informasi mulut-ke-mulut didefinisikan sebagai percakapan informal mengenai produk maupun jasa antar individu yang tidak memiliki hubungan dengan perusahaan produsen atau pemberi jasa (Silverman, 1997 dalam Choudhury, 2013

Promosi adalah upaya memperkenalkan produk atau jasa dengan tujuan menarik minat konsumen agar membeli atau menggunakan produk atau jasa yang ditawarkan. Promosi dilakukan untuk memperkenalkan produk maupun me-refresh pengetahuan konsumen akan produk yang sudah ada. Jenis sarana promosi misalnya: Iklan (advertising), promosi penjualan (sales promotion), penjualan personal (personal selling),publisitas (publicity), bauran promosi (Marketing Mix).

Keputusan berdeposito dipengaruh beberapa faktor penting seperti: tingkat suku bunga, pelayanan, kepercayaan/integritas, promosi, word of mouth atau informasi dari mulut ke mulut. Penelitian ini ingin mengetahui relevansi positif atau searah kelima faktor tersebut terhadap nilai deposito. Kerangka konseptual penelitian ini ditunjukkan grafik berikut: 


\section{saki}

Studi Akuntansi \& Keuangan Indonesia

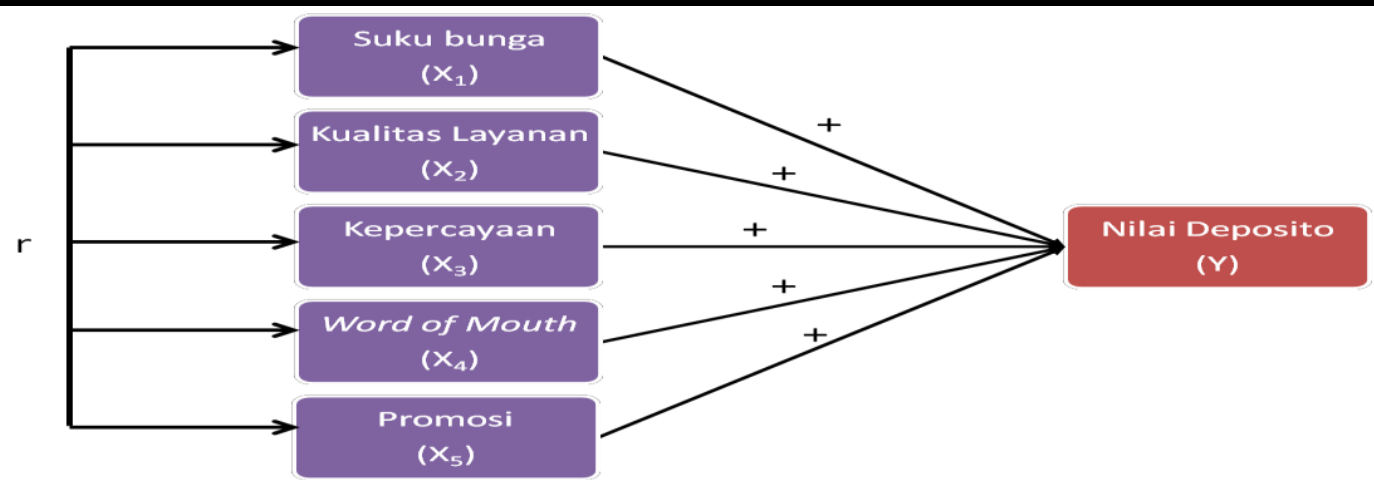

\section{Metode Penelitian}

Jenis penelitian ini ialah kuantitatif (data ordinal dan rasio) yang berasal dari data kualitatif (Sugiyono, 2004). Seluruh variabel bebas menggunakan skala likert. Skala yang digunakan ialah 1 (Sangat Tidak Setuju) sampai dengan 5 (Sangat Setuju). Variabel terikat diukur menggunakan data rasio yang menggambarkan angka sesungguhnya, bukan hanya sebagai simbol. Jenis data ini digunakan untuk melihat pengaruh antar variabel bebas dan terikat yang diuji. Pengujiannya menggunakan analisis regresi berganda untuk melihat besarnya pengaruh setiap variabel bebas terhadap variabel terikat.

Sumber data ialah data primer langsung (kuisioner) responden nasabah bank kategori BUKU 4. Kuesioner diakses secara online dan disebarkan secara langsung pada lokasi penelitian yang ditentukan. Variabel bebas yang digunakan ialah

1. Suku Bunga

Pengukuran variabel suku bunga dalam menilai faktor pengaruh pemilihan deposito menggunakan empat butir pertanyaan (Winda 2009).

2. Kualitas Layanan

Peneliti menggunakan instrumen Parasuraman et al. (1988) 6 butir pertanyaan untuk mengukur kualitas layanan pelanggan (perceived quality).

3. Kepercayaan

Peneliti menggunakan indikator pengukuran Gill et al. (2006) yang terdiri dari 5 butir pertanyaan.

4. Word of Mouth (WOM)

Alat ukur diambil dari penelitian Ohanian (1990), dalam Sweeney et al. (2014), yang terdiri dari 4 butir pertanyaan.

5. Promosi

Peneliti menggunakan indikator pengukuran Winda (2009)dengan jumlah pertanyaan 3 butir.

Pengukuran ke lima variable bebas menggunakan skala likert dengan bobot penilaian; 1=Sangat Tidak Setuju; 2=Tidak Setuju; 3=Netral/Ragu-ragu; 4=Setuju; 5=Sangat Setuju.

\section{Populasi dan Sampel}

Populasi penelitian ialah seluruh deposan Bank Umum Kelompok Usaha (BUKU) 4 yang memiliki simpanan deposito berjangka rupiah di Jabodetabek. Sampel yang digunakan adalah sistem Isaac dan Michael (1981). Berdasarkan rumus perhitungan jumlah sampel Isaac dan Michael, dengan jumlah populasi tidak diketahui dan taraf kesalahan 5\%, peneliti perlu mendapatkan responden minimal sebanyak 349 orang (Sugiyono, 2004).

\section{Metode Pengumpulan Data}

Peneliti menggunakan data primer untuk melakukan penyebaran kuesioner personal secara online dan langsung kepada deposan di Jabodetabek. Kuesioner diolah menggunakan 


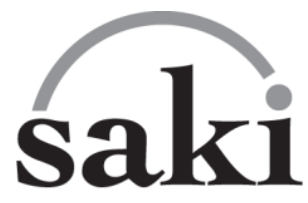

Studi Akuntansi \& Keuangan Indonesia

program SPSS 23, untuk pengujian hipotesa dan uji kelayakan kuesioner yang menilai tingkat validitas dan reliabilitas.

Dalam menggambarkan persepsi konsumen terhadap faktor-faktor yang mempengaruhi keputusan nasabah dalam memilih, peneliti menggunakan metode analisis deskriptif. Kualitas data diuji dengan menggunakan dua syarat yakni uji validitas dan uji reliabilitas. Peneliti menggunakan langkah-langkah Hays (1976) dalam mentransformasikan data ordinal menjadi interval.

Peneliti kemudian mengubah seluruh nilai ordinal kuesioner dengan analisis regresi linear berganda untuk melihat hubungan dan pengaruh variabel bebas dengan variabel terikat. Nilai setiap variabel bebas didapatkan dari penjumlahan skor interval atas pertanyaan untuk setiap variabel bebas yang diajukan kepada setiap responden. Skor interval didapatkan dari metode successive interval menggunakan data mentah responden.

Nilai variabel terikat (Y) atau nilai penempatan deposito nasabah disederhanakan sebelum dilakukan. Penyederhanaan data dilakukan dengan mengubah data nilai deposito menggunakan logaritma natural (ln e). Peneliti menggunakan aplikasi Software SPSS 23 dalam mentransformasi data nilai deposito menjadi logaritma natural (ln e).

Untuk memastikan pengaruh variabel bebas yang diteliti berpengaruh positif dan signifikan terhadap variabel terikat, peneliti menggunakan Uji-F (uji serentak) dan Uji-t (uji parsial), dan identifikasi Determinan $\left(\mathrm{R}^{2}\right)$. Sebelum menganalisis data kuantitatif, diadakan uji persyartaan analisis regresi berganda melalui uji asumsi autokorelasi, multikolinearitas, heteroskedastisitas, dan normalitas. Peneliti menggunakan Uji korelasi Spearman untuk mengetahui pengaruh signifikan dan searah hubungan variabel bebas dengan variabel terikat. Penggunaan uji korelasi Spearman merupakan uji statistik nonparametrik didasarkan pada jenis data ordinal dan rasio.

\section{ANALISIS DAN HASIL}

Penelitian ini menggunakan data primer melalui kuisioner online dengan jumlah responden 405 orang yang berdeposito pada Bank BUKU 4. Jumlah pertanyaannya 22 butir berkaitan dengan variabel X; 4 butir pertanyaan untuk variabel suku bunga (X1), 6 butir pertanyaan untuk variabel kualitas layanan (X2), 5 butir pertanyaan untuk variabel kepercayaan (X3), 4 butir pertanyaan untuk variabel word of mouth (X4), dan 3 butir pertanyaan untuk variabel promosi (X5).

Peneliti juga mengajukan pertanyaan terkait identitas responden dan nilai deposito yang dimiliki. Identitas 405 responden diklasifikasikan berdasarkan: jenis kelamin, usia, pendidikan, pekerjaan, pengeluaran bulanan, tempat tinggal, jangka waktu deposito, dan bank yang digunakan. Setiap butir pertanyaan tanggapan yang dapat diberikan responden terdiri dari 5 pilihan yakni Sangat Setuju (SS) dengan skor 5, Setuju (S) dengan skor 4, Ragu-Ragu (RG) dengan skor 3, Tidak Setuju (TS) dengan skor 2, dan Sangat Tidak Setuju (STS) dengan skor.

\section{Variabel Suku Bunga sebagai Variabel X1}

Berikut adalah tabel Distribusi Pendapat Responden terhadap Variabel Suku Bunga pada pertanyaan 1. Suku bunga deposito yang diberikan bank tinggi sesuai dengan LPS. 2. Suku bunga deposito yang ditawarkan bank lebih tinggi dibandingkan dengan suku bunga deposito bank lainnya. 3 Bank memberikan special rate yang tinggi untuk nominal simpanan deposito tertentu. 4. Bank memberikan special rate yang untuk simpanan pada jangka waktu tertentu.

\begin{tabular}{|c|c|c|c|c|c|c|c|c|c|c|}
\hline \multirow{2}{*}{$\begin{array}{l}\text { Item } \\
\text { Pertanyaa }\end{array}$} & \multicolumn{2}{|c|}{ STS (1) } & \multicolumn{2}{|c|}{ TS (2) } & \multicolumn{2}{|c|}{ RG (3) } & \multicolumn{2}{|c|}{ S (4) } & \multicolumn{2}{|c|}{ SS (5) } \\
\cline { 2 - 11 } & $\mathbf{F}$ & $\boldsymbol{\%}$ & $\mathbf{F}$ & $\boldsymbol{\%}$ & $\mathbf{F}$ & $\boldsymbol{\%}$ & $\mathbf{F}$ & $\boldsymbol{\%}$ & $\mathbf{F}$ & $\boldsymbol{\%}$ \\
\hline 1 & 12 & $2.96 \%$ & 28 & $6.91 \%$ & 74 & $18.27 \%$ & 210 & $51.85 \%$ & 81 & $20.00 \%$ \\
\hline
\end{tabular}




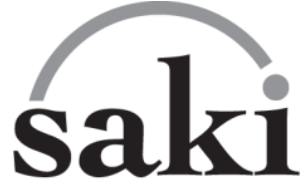

Studi Akuntansi \& Keuangan Indonesia

\begin{tabular}{|c|c|c|c|c|c|c|c|c|c|c|}
\hline 2 & 12 & $2.96 \%$ & 38 & $9.38 \%$ & 172 & $42.47 \%$ & 141 & $34.81 \%$ & 42 & $10.37 \%$ \\
\hline 3 & 11 & $2.72 \%$ & 45 & $11.11 \%$ & 134 & $33.09 \%$ & 169 & $41.73 \%$ & 46 & $11.36 \%$ \\
\hline 4 & 12 & $2.96 \%$ & 47 & $11.60 \%$ & 130 & $32.10 \%$ & 177 & $43.70 \%$ & 39 & $9.63 \%$ \\
\hline
\end{tabular}

\section{Variabel Kualitas Layanan sebagai Variabel X2}

Berikut adalah tabel distribusi Pendapat Responden terhadap Variabel Kualitas Layanan, pada pertanyaan 1. Pegawai bank selalu berusaha memenuhi permintaan saya. 2. Perilaku setiap pegawai bank menanamkan kepercayaan bagi nasabah. 3. Pegawai bank memiliki kemampuan yang baik dalam menjawab segala pertanyaan saya. 4. Pegawai bank selalu bersikap ramah kepada setiap nasabahnya. 5. Bank memiliki kantor-kantor cabang yang keberadaannya mudah dijangkau. 6. Pegawai bank memberikan pelayanan yang cepat.

\begin{tabular}{|c|c|c|c|c|c|c|c|c|c|c|}
\hline \multirow{2}{*}{$\begin{array}{c}\text { Item } \\
\text { Pertanyaan }\end{array}$} & \multicolumn{2}{|c|}{ STS (1) } & \multicolumn{2}{|c|}{ TS (2) } & \multicolumn{2}{|c|}{ RG (3) } & \multicolumn{2}{|c|}{ S (4) } & \multicolumn{2}{c|}{ SS (5) } \\
\cline { 2 - 10 } & F & $\%$ & F & \% & F & \% & F & $\%$ & F & $\%$ \\
\hline 1 & 0 & $0.00 \%$ & 3 & $0.74 \%$ & 26 & $6.42 \%$ & 213 & $52.59 \%$ & 163 & $40.25 \%$ \\
\hline 2 & 0 & $0.00 \%$ & 6 & $1.48 \%$ & 22 & $5.43 \%$ & 239 & $59.01 \%$ & 138 & $34.07 \%$ \\
\hline 3 & 0 & $0.00 \%$ & 8 & $1.98 \%$ & 29 & $7.16 \%$ & 243 & $60.00 \%$ & 125 & $30.86 \%$ \\
\hline 4 & 0 & $0.00 \%$ & 5 & $1.23 \%$ & 40 & $9.88 \%$ & 225 & $55.56 \%$ & 135 & $33.33 \%$ \\
\hline 5 & 0 & $0.00 \%$ & 12 & $2.96 \%$ & 56 & $13.83 \%$ & 169 & $41.73 \%$ & 168 & $41.48 \%$ \\
\hline 6 & 0 & $0.00 \%$ & 3 & $0.74 \%$ & 73 & $18.02 \%$ & 229 & $56.54 \%$ & 100 & $24.69 \%$ \\
\hline
\end{tabular}

\section{Variabel Kepercayaan sebagai Variabel X3}

Berikut adalah tabel distribusi Pendapat Responden terhadap Variabel Kepercayaan pada pertanyaan 1; Bank dapat dipercaya dalam mengelola dana nasabahnya. 2. Bank memiliki integritas yang tinggi. 3. Bank selalu menjaga kerahasiaan informasi transaksi nasabahnya. 4. Pegawai bank memiliki standar yang tinggi dalam setiap pekerjaannya. 5. Pegawai bank jujur.

\begin{tabular}{|c|c|c|c|c|c|c|c|c|c|c|}
\hline \multirow{2}{*}{\begin{tabular}{l}
\multirow{2}{*}{$\begin{array}{l}\text { Item } \\
\text { nertanyaa }\end{array}$} \\
\cline { 2 - 11 }
\end{tabular}} & \multicolumn{2}{|c|}{ STS (1) } & \multicolumn{2}{|c|}{ TS (2) } & \multicolumn{2}{|c|}{ RG (3) } & \multicolumn{2}{|c|}{ S (4) } & \multicolumn{2}{c|}{ SS (5) } \\
\hline 1 & 0 & $0.00 \%$ & 0 & $0.00 \%$ & 34 & $8.40 \%$ & 229 & $56.54 \%$ & 142 & $35.06 \%$ \\
\hline 2 & 0 & $0.00 \%$ & 0 & $0.00 \%$ & 23 & $5.68 \%$ & 253 & $62.47 \%$ & 129 & $31.85 \%$ \\
\hline 3 & 0 & $0.00 \%$ & 13 & $3.21 \%$ & 31 & $7.65 \%$ & 203 & $50.12 \%$ & 158 & $39.01 \%$ \\
\hline 4 & 0 & $0.00 \%$ & 46 & $11.36 \%$ & 93 & $22.96 \%$ & 185 & $45.68 \%$ & 81 & $20.00 \%$ \\
\hline 5 & 0 & $0.00 \%$ & 3 & $0.74 \%$ & 88 & $21.73 \%$ & 241 & $59.51 \%$ & 73 & $18.02 \%$ \\
\hline
\end{tabular}

\section{Variabel Word of Mouth sebagai Variabel X4}

Berikut adalah tabel distribusi Pendapat Responden terhadap Variabel Word of Mouth (Sumber Data primer, 2016 yang telah diolah), pada pertanyaan 1; Saya mengetahui informasi tentang bank dari nasabah yang telah memiliki pengalaman di bank ini. 2. Saya mengetahui informasi tentang bank saya ini dari nasabah yang memiliki pengetahuan luas tentang perbankan. 3. Saya mengetahui informasi tentang bank dari kerabat yang memiliki hubungan yang dekat. 4 . Saya mengetahui informasi tentang bank dari kerabat yang memiliki ketertarikan yang sama dengan saya. 


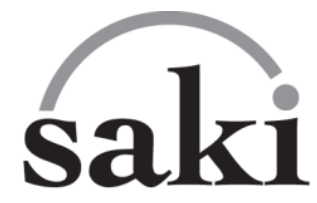

Studi Akuntansi \& Keuangan Indonesia

\begin{tabular}{|c|c|c|c|c|c|c|c|c|c|c|}
\hline \multirow{2}{*}{$\begin{array}{l}\quad \text { Item } \\
\text { Pertanyaa } \\
n\end{array}$} & \multicolumn{2}{|c|}{ STS (1) } & \multicolumn{2}{|c|}{ TS (2) } & \multicolumn{2}{|c|}{ RG (3) } & \multicolumn{2}{|c|}{ S (4) } & \multicolumn{2}{|c|}{ SS (5) } \\
\hline & $\mathbf{F}$ & $\%$ & $\mathbf{F}$ & $\%$ & $\mathbf{F}$ & $\%$ & $\mathbf{F}$ & $\%$ & $\mathbf{F}$ & $\%$ \\
\hline 1 & 27 & $6.67 \%$ & 77 & $19.01 \%$ & 90 & $22.22 \%$ & 164 & $40.49 \%$ & 47 & $11.60 \%$ \\
\hline 2 & 22 & $5.43 \%$ & 113 & $27.90 \%$ & 73 & $18.02 \%$ & 137 & $33.83 \%$ & 60 & $14.81 \%$ \\
\hline 3 & 18 & $4.44 \%$ & 81 & $20.00 \%$ & 59 & $14.57 \%$ & 179 & $44.20 \%$ & 68 & $16.79 \%$ \\
\hline 4 & 20 & $4.94 \%$ & 80 & $19.75 \%$ & 112 & $27.65 \%$ & 175 & $43.21 \%$ & 18 & $4.44 \%$ \\
\hline
\end{tabular}

\section{Variabel Promosi sebagai Variabel X5}

Berikut adalah tabel distribusi Pendapat Responden terhadap Variabel Promosi (Sumber Data primer, 2016 yang telah diolah), pada pertanyaan 1; Bank melakukan promosi melalui iklan di media cetak maupun elektronik yang menarik. 2. Bank aktif melakukan kegiatan promosi dengan teknik personal selling. 3. Bank sering memberikan penawaran khusus kepada nasabahnya.

\begin{tabular}{|c|c|c|c|c|c|c|c|c|c|c|}
\hline \multirow{2}{*}{$\begin{array}{l}\text { Item } \\
\text { Pertanyaa } \\
\text { n }\end{array}$} & \multicolumn{2}{|c|}{ STS (1) } & \multicolumn{2}{c|}{ TS (2) } & \multicolumn{2}{c|}{ RG (3) } & \multicolumn{2}{|c|}{ S (4) } & \multicolumn{2}{c|}{ SS (5) } \\
\cline { 2 - 11 } & F & $\%$ & F & \% & F & \% & F & \% & F & $\%$ \\
\hline 1 & 19 & $4.69 \%$ & 120 & $29.63 \%$ & 139 & $34.32 \%$ & 114 & $28.15 \%$ & 13 & $3.21 \%$ \\
\hline 2 & 13 & $3.21 \%$ & 46 & $11.36 \%$ & 106 & $26.17 \%$ & 207 & $51.11 \%$ & 33 & $8.15 \%$ \\
\hline 3 & 12 & $2.96 \%$ & 64 & $15.80 \%$ & 131 & $32.35 \%$ & 170 & $41.98 \%$ & 28 & $6.91 \%$ \\
\hline
\end{tabular}

\section{Variabel Nilai Deposito sebagai Variabel Y}

Berdasarkan Nilai Penempatan Deposito Responden Promosi, lebih dari 251 orang atau $61,98 \%$ responden memiliki nilai penempatan deposito kurang dari sama dengan Rp 50.000.000, 80 orang atau $19,75 \%$ responden memiliki nilai penempatan deposito pada rentang $\mathrm{Rp}$ 50.000.000 sampai dengan Rp 100.000.000, 68 orang memiliki deposito sebesar Rp 100.000.000 hingga Rp 500.000.000, sebanyak 6 orang responden yang memiliki deposito di atas Rp 500.000.000. Hal ini menunjukkan bahwa mayoritas responden memiliki dana deposito sebanyak kurang dari Rp 50.000.000 pada Bank BUKU 4.

\section{Analisis Regresi Berganda}

Uji kelayakan kuesioner dilakukan dengan menyebarkan kuesioner awal kepada 30 responden dengan 44 butir pertanyaan untuk variabel bebas (X), 1 pertanyaan untuk variabel terikat (Y), dan 6 pertanyaan data diri responden. Hasil dari kuesioner awal diuji validitas dan reliabilitasnya menggunakan program SPSS 23. Dari hasil olah data sistem Pearson (uji validitas $1,2,3$ ) terdapat 22 butir pertanyaan valid dengan $r$ hitung lebih besar dari 0,361 .

Peneliti melakukan peningkatan skala pengukuran ordinal menjadi interval menggunakan metode successive interval. Langkah-langkahnya adalah Menghitung Frekuensi, Menghitung Proporsi (P), Menghitung Proporsi Kumulatif (Pk), Mencari Nilai Z, Menghitung Densitas F (z), Menghitung Scale Value, dan Menghitung Nilai Hasil Penskalaan. Data yang telah diubah dengan angka-angka kemudian digunakan untuk uji hipotesa dengan metode analisis regresi berganda yang bertujuan mengetahui pengaruh dan hubungan antara variabel bebas dengan variabel terikat. Data yang digunakan adalah: Nilai variabel bebas (X1 sampai dengan X5) untuk setiap responden didapatkan dari penjumlahan nilai interval setiap pertanyaan yang menggambarkan setiap variabel bebas dan Nilai variabel terikat (Y) atau nilai deposito masingmasing responden merupakan hasil transformasi data menggunakan logaritma natural (ln e).

Data yang diperoleh diolah menggunakan aplikasi software SPSS 23 dengan hasil: 


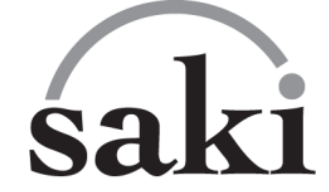

Studi Akuntansi \& Keuangan Indonesia

1. Variabel suku bunga berpengaruh positif dan signifikan terhadap nilai penempatan deposito nasabah pada Bank BUKU 4 dengan nilai signifikansi di bawah nilai $\alpha=0,05$ dan koefisien sebesar 1,135. Artinya, apabila terjadi peningkatan pada persepsi kepuasan nasabah akan suku bunga yang diberikan bank, nilai penempatan deposito nasabah akan meningkat pula, dengan asumsi bahwa variabel lain dianggap konstan.

2. Variabel kualitas layanan memiliki nilai signifikansi lebih besar dari $\alpha=0,05$ yang berarti tidak cukup bukti untuk menyatakan bahwa variabel ini berpengaruh signifikan terhadap nilai penempatan deposito nasabah pada Bank BUKU 4.

3. Variabel kepercayaan terbukti memiliki pengaruh positif dan signifikan terhadap nilai penempatan deposito nasabah individu pada Bank BUKU 4, dengan nilai signifikansi sebesar 0,047 lebih kecil dibandingkan nilai $\alpha=0,05$. Adapun koefisiennya yakni 1,059. Artinya, jika terjadi peningkatan pada persepsi kepercayaan nasabah terhadap bank, maka akan terjadi peningkatan pada nilai penempatan deposito nasabah pada deposito Bank BUKU 4.

4. Variabel word of mouth memiliki nilai signifikansi 0,820 lebih besar dari nilai $\alpha=0,05$. artinya, variabel word of mouth tidak berpengaruh secara signifikan terrhadap nilai penempatan deposito nasabah pada Bank BUKU 4.

5. Variabel promosi memiliki nilai signifikansi sebesar 0,778 yang lebih besar dari nilai $\alpha=$ 0,05. Variabel promosi tidak berpengaruh positif dan signifikan terhadap nilai penempatan deposito nasabah pada Bank BUKU 4.

Hasil yang didapat diuji menggunakan Uji-F atau uji serentak untuk melihat apakah variabel bebas secara bersama-sama memiliki pengaruh yang signifikan terhadap variabel terikat. Hasilnya adalah variabel suku bunga, kualitas layanan, kepercayaan, word of mouth, dan promosi secara bersama-sama memiliki pengaruh yang signifikan terhadap nilai penempatan deposito nasabah pada Bank BUKU4.

Peneliti juga menggunakan Uji-t atau uji parsial untuk melihat besarnya pengaruh variabel bebas secara individu terhadap variabel terikat yang diuji. Hasilnya adalah:

1. Semakin tinggi persepsi kepuasan nasabah akan tingkat suku bunga yang ditawarkan bank, semakin tinggi juga nilai penempatan deposito nasabah pada bank tersebut. Hal tersebut mendukung dari sisi investasi karena masyarakat berinvestasi melalui deposito menginginkan suku bunga yang setinggi- tingginya karena memberikan pendapatan investasi yang menguntungkan.

2. Kualitas layanan yang diberikan kepada nasabah tidak berperan secara signifikan terhadap nilai penempatan deposito nasabah individu pada Bank BUKU 4. Kemungkinan lain yang terjadi ialah pelayanan yang diberikan belum cukup memuaskan nasabah sehingga belum dapat mempengaruhi nilai penempatan deposito nasabah secara signifikan.

3. Nasabah mempercayai bank untuk berdeposito. Rasa aman berinvestasi dalam jangka waktu tertentu merupakan salah satu hal yang penting bagi nasabah. Nasabah dapat dikatakan percaya bahwa dana yang mereka tempatkan berada pada bank yang tepat, dan nasabah juga yakin bahwa mereka akan mendapatkan dana mereka kembali dengan jumlah bunga tertentu yang diberikan oleh bank.

4. Variabel word of mouth tidak berpengaruh signifikan terhadap nilai penempatan deposito nasabah pada Bank BUKU 4. Hasil pembicaraan atau rekomendasi terhadap suatu bank dari kerabat ataupun relasi tampaknya tidak berpengaruh signifikan terhadap nilai penempatan deposito nasabah.

5. Promosi tidak berpengaruh signifikan terhadap nilai penempatan deposito nasabah pada Bank BUKU 4. Promosi yang dilakukan oleh Bank BUKU 4 melalui iklan media cetak ataupun elektronik, metode personal selling yang dilakukan bank, serta penawaranpenawaran khusus yang diberikan bank belum dapat mempengaruhi nilai penempatan 


\section{saki}

Studi Akuntansi \& Keuangan Indonesia

\section{deposito secara signifikan.}

Hasil uji-t diperkuat dengan melakukan Identifikasi Determinan $\left(\mathrm{R}^{2}\right)$ untuk mengetahui pengaruh dari model yang digunakan. Hasilnya adalah bahwa variabel suku bunga, kualitas layanan, kepercayaan, word of mouth, dan promosi dapat menjelaskan sebesar 6,2\% terhadap faktor-faktor yang mempengaruhi nilai penempatan deposito nasabah pada Bank BUKU 4.

Kesimpulan Analisis Regresi Linear Berganda diperkuat oleh Uji Asumsi Klasik yang meliputi: Uji Asumsi Autokorelasi, Uji Asumsi Multikolinearitas, Uji Asumsi, Heteroskedastisitas, Uji Asumsi Normalitas; dan uji Korelasi Spearman.

\section{Analisis Regresi Kategori Usia}

Pada kategori Usia 30 tahun (jumlah responden209) disimpulkan bahwa secara serentak, variabel suku bunga, kualitas layanan, kepercayaan, word of mouth, dan promosi berpengaruh signifikan terhadap nilai penempatan deposito nasabah individu yang berusia di bawah atau sama dengan 30 tahun pada Bank BUKU 4.

Pada kategori usia 31-40 tahun (jumlah 68 responden), suku bunga, kualitas layanan, kepercayaan, word of mouth, dan promosi berpengaruh terhadap nilai penempatan deposito nasabah pada Bank BUKU 4. Diketahui bahwa variabel word of mouth dan promosi adalah faktor-faktor yang secara positif dan signifikan mempengaruhi nilai penempatan deposito di Bank BUKU .

Pada kategori usia 41-50 tahun (jumlah responden 58): suku bunga, kualitas layanan, kepercayaan, word of mouth, dan promosi berpengaruh signifikan terhadap nilai penempatan deposito nasabah pada Bank BUKU 4. Hanya faktor kepercayaan yang berpengaruh positif dan signifikan terhadap nilai penempatan deposito nasabah individu pada usia 41-50 tahun di Bank BUKU 4, yakni sebanyak 58 orang. Hal ini berarti jika terjadi peningkatan pada persepsi kepercayaan nasabah terhadap bank, maka akan terjadi peningkatan pada nilai penempatan deposito nasabah pada Bank BUKU 4.

Pada Kategori usia di atas 50 tahun (jumlah responden 70): Seluruh variabel bebas yakni suku bunga, kualitas layanan, kepercayaan, word of mouth, dan promosi berpengaruh signifikan terhadap nilai penempatan deposito. Secara parsial, didapatkan hasil bahwa hanya variabel kualitas layanan yang berpengaruh positif dan signifikan terhadap nilai penempatan deposito nasabah individu yang berusia di atas 50 tahun pada Bank BUKU 4.

\section{KESIMPULAN}

Melalui Uji-F atau uji serentak, seluruh variabel bebas berpengaruh signifikan terhadap variabel terikat dengan nilai signifikansi sebesar 0,000 yang lebih kecil dari nilai $\alpha=0,05$. Melalui Uji-t atau uji parsial, hanya variabel suku bunga dan variabel kepercayaan yang berpengaruh positif dan signifikan terhadap nilai penempatan deposito nasabah individu pada Bank BUKU 4. Variabel kualitas layanan, word of mouth, dan promosi tidak terbukti memiliki pengaruh signifikan terhadap nilai penempatan deposito oleh nasabah individu pada Bank BUKU 4.

Analisis koefisien determinasi $\left(\mathrm{R}^{2}\right)$ menghasilkan nilai Adjusted $R$ Square $\left(\mathrm{R}^{2}\right)$ sebesar 0,062, artinya nilai penempatan deposito nasabah individu pada Bank BUKU 4 dijelaskan menggunakan variabel suku bunga, kualitas layanan, kepercayaan, word of mouth, dan promosi sebesar $6,2 \%$.

Dari uji korelasi Spearman, didapatkan hasil variabel suku bunga dan kepercayaan berpengaruh positif dan signifikan terhadap nilai penempatan deposito nasabah pada Bank BUKU 4. Variabel kualitas layanan, word of mouth, dan promosi tidak berpengaruh terhadap 


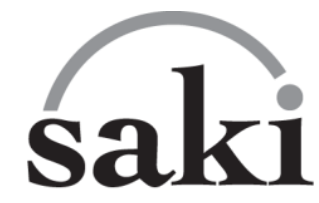

Studi Akuntansi \& Keuangan Indonesia

nilai penempatan deposito tersebut.

Pada usia di bawah atau sama dengan 30 tahun, variabel promosi berpengaruh positif dan signifikan terhadap nilai penempatan deposito nasabah. Pada kategori usia 31-40 tahun, variabel word of mouth dan promosi berpengaruh terhadap nilai penempatan deposito nasabah individu secara positif dan signifikan. Pada usia 41-50 tahun, variabel kepercayaan berpengaruh secara positif dan signifikan pada nilai penempatan deposito nasabah individu. Untuk kategori usia di atas 50 tahun, variabel kualitas layanan berpengaruh positif dan signifikan terhadap nilai penempatan deposito nasabah individu.

Hasil analisis bahwa variabel kepercayaan memiliki pengaruh positif dan signifikan terhadap nilai penempatan dana nasabah individu pada Bank BUKU 4 sejalan dengan teori dasar fungsi bank sebagai agent of trust.

Hasil penelitian ini mendukung penelitian Winda (2009) bahwa suku bunga berpengaruh signifikan terhadap keputusan nasabah memilih deposito, dan juga penelitian yang dilakukan oleh Khusnul Khotimah (2013) bahwa faktor kepercayaan berpengaruh signifikan terhadap loyalitas nasabah menabung.

Bank yang berusaha meningkatkan perolehan dana dari produk deposito nasabah individu, sebaiknya memperhatikan penetapan tingkat suku bunga agar dapat berkompetisi dengan bank lain. Hal ini harus diiringi dengan usaha mempertahankan serta meningkatkan kepercayaan terhadap bank, dengan tetap memperhatikan tingkat kesehatan bank agar berada pada level aman dan sesuai dengan regulasi pemerintah.

Bank diharapkan senantiasa meningkatkan kualitas layanan yang diberikan kepada nasabah, khususnya yang berusia di atas 50 tahun, agar meningkatkan kepuasan nasabah dalam bertransaksi. Hal ini meliputi sikap serta kemampuan pegawai dalam mengerjakan pekerjaannya, juga strategi bank dalam menempatkan kantor cabang yang mudah dijangkau oleh nasabah. Bank perlu memperhatikan strategi promosi untuk meningkatkan kepuasan nasabah (yang masih berusia muda atau di bawah 50 tahun) sehingga berdampak pada nilai penempatan dana deposito di bank tersebut.

\section{DAFTAR PUSTAKA}

Almilia, L.S. \& Utomo, A.W. (2006). Faktor-faktor yang Mempengaruhi Tingkat Suku Bunga Deposito Berjangka Pada Bank Umum di Indonesia. Jurnal Ekonomi dan Bisnis ANTISIPASI, Vol. 10. No.1.

Ananth, A., Ramesh, R. \& Prabaharan, B.(2011). Service Quality GAP Analysis in Private Sector Banks A Customer Perspective, Internationally Indexed Journal. Vol. II Issue 1. Hal. 245-252.

Andaleeb, S.S. (1992). The Trust Concept: Research Issues for Channel of Distribution, Research in Marketing. Vol. 11. Hal. 1-34.

Chandran, R. \& Ho, Y. (2015, Oktober 14). http://www.bloomberg.com/news/articles. (In text reference: (Indonesia's Outlook Changed to Positive From Stable at S\&P, 2015)

Chatterje, S. \& Hadi, A.S. ( 2006). Regression Analysis by Example. Edisi 4, United States: John Wiley and Sons Ltd.

Choudhury, K. (2013). Service Quality and Word of Mouth: A Study of the Banking Sector, International Journal of Bank Marketing, Vol. 32 Iss 7. Hal.612-627.

Coulter, K.S. \& Coulter, R.A. (2002). Determinants of Trust in a Service Provider: The Moderating Role of Length of Relationship, Journal of Services Marketing, Vol. 16 Iss 1. Hal. 35-50.

Desyani, A. (2014, Oktober 14). http://travel.tempo.co/read/news/. In text reference: (Indonesia Negara Tujuan Investasi Jangka Panjang, 2014) 


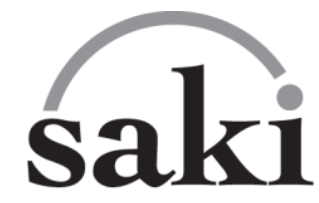

Studi Akuntansi \& Keuangan Indonesia

Gill, A.S., Flaschner, A.B. \& Shachar, M. (2006). Factors that Affect the Trust of Business Clients in Their Banks, International Journal of Bank Marketing, Vol. 24 No. 6. Hal. 384-405.

Gilly, M.C., Graham, J.L., Wolfinbarger, M.F. \& Yale, L.J. (1998). A Dyadic Study of Interpersonal Information Search, Journal of the Academy of Marketing Science, Vol. 26 No. 2. Hal. 83-100.

Gujarati, D.N. (2006). Basic Econometrics. Edisi 4. New York: McGraw-Hill/Irwin.

Hays, W.L. (1976). Quantification in Psychology. New Delhi: Prentice Hall.

Istyaningsih, R. (2015). Studi Perilaku Tentang Pengaruh Karakteristik Nasabah Dalam Memilih Deposito Berjangka, Jurnal Ilmiah CIVIS, Vol. V No. 1.

Kasmir, (2005). Pemasaran Bank. Jakarta: Kencana.

Kasmir, 2008. Bank dan Lembaga Keuangan Lainnya. Jakarta: PT. RAJAGRAFINDO PERSADA.

Kasmir. (2012). Dasar-dasar Perbankan. Jakarta: PT. RAJAGRAFINDO PERSADA.

Khotimah, K. (2013). Pengaruh Kepercayaan terhadap Loyalitas Nasabah Menabung pada Kantor Cabang Utama PT. Bank Pembangunan Daerah Papua di Jayapura, Jurnal FuturE, Vol. 1 No. 1.

Kotler, P. (1997). Marketing Management "Analysis, Planning, Implementation and Control". Edisi 9, New Jersey: Prentice Hall International, Inc.

Kumar, M., Kee, F. \& Manshor, A. (2009). Determining the Relative Importance of Critical Factors in Delivering Service Quality of Banks: An Application of Dominance Analysis in SERVQUAL Model, Managing Service Quality, Vol. 19 Iss. 2. Hal. 211-228.

Lembaga Penjamin Simpanan, (2005, Oktober 14). http://www.lps.go.id/web. In text reference : (Sejarah Pendirian LPS. 2014).

Lubis, I. (2010). Bank dan Lembaga Keuangan Lain. Medan: USU Press.

Malhotra, N.K. \& Birks, D.F. (2007). Marketing Research: An Applied Approach. Harlow: Prentice Hall/Financial Times.

Montgomery, D.C., Peck, E.A. \& Vining, G.G. (2012). Introduction to Linear Regression Analysis. Edisi 5, United Kingdom: John Wiley and Sons Ltd.

Moorman, C., Deshpande, R. \& Zaltman, G. (1992). Relationships Between Providers and Users of Market Research: The Dynamics of Trust Within and Between Organizations, Journal of Marketing Research, Vol. 29 No. 3. Hal. 314-29.

Novianto, A.S. \& Hadiwidjojo, D. (2013). Analisis Faktor-faktor yang Mempengaruhi Penghimpunan Deposito Mudharabah Perbankan Syariah di Indonesia, Jurnal Aplikasi Manajemen, Vol. 11 No. 4.

O'Hanian, R. (1990). Construction and Validation of a Scale to Measure Celebrity Endorsers' Perceived Expertise, Trustworthiness and Attractiveness, Journal of Advertising, Vol. 19 No. 3. Hal. 39-52.

Oliver, R., 1980. A Cognitive Model of the Antecedents and Consequences of Satisfaction Decisions, Journal of Marketing Research, Vol. 17. Hal. 460-469.

Parasuraman, A., Zeithaml, V.A. \& Berry, L.L. (1988). Servqual: A Multiple-Item Scale for Measuring Consumer Perceptions of Service Quality, Journal of Retailing, Vol. 64 No. 1. Hal. 12-40.

Parasuraman, A., Zeithaml, V.A. \& Berry, L.L. (1994). Alternative Scales for Measuring Service Quality: A Comparative Assessment Based on Psychometric and Diagnostic Criteria, Journal of Retailing, Vol. 70 No. 3. Hal. 201-230.

Pasaleori, F. (2012). Pengaruh Promosi dan Tingkat Suku Bunga terhadap Perolehan Dana Pihak Ketiga (Deposito BNI) PT. Bank Negara Indonesia (Persero) Tbk Cabang XX Wilayah 07. Skripsi. Universitas Hasanuddin Makassar.

Bank Indonesia. (2012). Peraturan Bank Indonesia Nomor 14/26/PBI/2012 tentang Kegiatan 


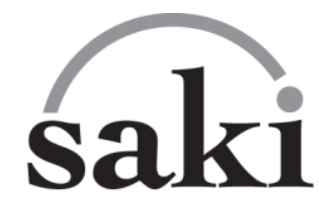

Studi Akuntansi \& Keuangan Indonesia

Usaha Dan Jaringan Kantor Berdasarkan Modal Inti Bank. Jakarta: Bank Indonesia.

Sadek, D., Zainal, N., Taher, M. \& Yahya, A. (2010). Service Quality Perceptions between Cooperative and Islamic Banks of Britain, American Journal of Economics and Business Administration, Vol.2 No.1. Hal. 1-5.

Saghier, N. E. dan Nathan, D. (2013). Service Quality Dimensions and Customers' Satisfactions of Banks in Egypt. International Business Research Conference.

Sekaran, Uma, dan Bougie, R. (2013). Research Method for Business. Edisi 6, United Kingdom: John Wiley and Sons Ltd.

Setiadi, N.J. (2005). Perilaku Konsumen: Konsep dan Implikasi untuk Strategi dan Penelitian Pemasaran. Jakarta: Prenada Media.

Silverman, G. (1997). How to Harness the Awesome Power of Word-of-Mouth, Direct Marketing, November. Hal. 32-37.

Suhendra, (2014, Februari 19). http://finance.detik.com/read/. In text reference: (Jabodetabek: Calon Megapolitan Terbesar ke-2 di Dunia, 2014).

Sulaiman, F. (2015, Maret 25). http://wartaekonomi.co.id/read/. In text reference: (DPR: Jumlah Bank di Indonesia seperti Jamur. 2015).

Sugiyono. (2004). Metode Penelitian Kuantitatif, Kualitatif dan R\&D. Bandung: Alfabeta.

Sugiyono, 2009. Metode Penelitian Bisnis. Bandung: Alfabeta.

Sweeney, J., Soutar, G. \& Mazzarol, T. (2014). Factors Enhancing Word-of-Mouth Influence: Positive and Negative Service-Related Messages, European Journal of Marketing, Vol. 48 Iss 1/2. Hal. 336-359.

Tambunan, M.R. \& Nasution, I.G.S. (2013). Analisis Faktor-faktor yang Mempengaruhi Keputusan Nasabah Menabung di Bank BCA Kota Medan (Studi Kasus Etnis Cina), Jurnal Ekonomi dan Keuangan, Vol. 1 No. 3.

Republik Indonesia. (1998). Undang-undang No. 10 tahun 1998 tentang Perubahan atas Undang-undang No. 7 tahun 1992 tentang Perbankan. Lembaran Negara RI Tahun 1998, No. 182. Jakarta: Sekretariat Negara.

Walter, A., Mueller, T.A. \& Helfert, G. (2001). The Impact of Satisfaction, Trust, and Relationship Value on Commitment: Theoretical Considerations and Empirical Results. University of Karlsruhe. Germany.

Winda. (2009). Analisis Faktor-Faktor yang Mempengaruhi Keputusan Nasabah Deposito PT. Bank Tabungan Pensiunan Nasional, Tbk Cabang Medan. Skripsi. Universitas Sumatera Utara.

Yang, Z. \& Fang, X. (2004). Online Service Quality Dimensions and Their Relationships with Satisfaction: A Content Analysis of Customer Reviews of Securities Brokerage Services, International Journal of Service Industry Management, Vol. 15 Issue: 3. Hal. 302-326.

Zeithaml, V. (2000). Service Quality, Profitability and the Economic Worth of Customers: What We Know and What We Need to Learn, Journal of the Academy of Marketing Science, Vol. 28 No. 1, Hal. 67-85.

Zineldin, M. (1995). Bank-company Interactions and Relationships: Some Empirical Evidence, International Journal of Bank Market ing, Vol. 13 No. 2, Hal. 30-43. 